\title{
Educação Física escolar no desenvolvimento da psicomotricidade
}

\author{
School Physical Education in the development of psychomotricity \\ La Educación Física Escolar en el desarrollo de la psicomotricidade
}

\author{
Henrique Marques Martins \\ ORCID: https://orcid.org/0000-0001-6784-5110 \\ Faculdade de Mauá Brasília, Brasil \\ E-mail: henriqmarqs@gmail.com \\ Givanildo de Oliveira Santos \\ ORCID: https://orcid.org/0000-0001-5279-1535 \\ Faculdade de Mauá Brasília, Brasil \\ E-mail: givanildo-o@hotmail.com \\ Diego Maxwell Soares Ribeiro \\ ORCID: https://orcid.org/0000-0001-8139-001X \\ Faculdade de Mauá Brasília, Brasil \\ E-mail: diegomsribeiroprof@gmail.com \\ Samir Jamil Jaber \\ ORCID: https://orcid.org/0000-0002-9945-1754 \\ Universidade Federal de Goiás, Brasil \\ E-mail: samirjaber11@hotmail.com \\ Sebastião Lobo da Silva \\ ORCID: https://orcid.org/0000-0003-2639-0898 \\ Universidade Católica de Brasília, Brasil \\ E-mail: slobo2011@gmail.com
}

\begin{abstract}
Resumo
A Educação Física aparece com grande responsabilidade na escola, estruturando o ambiente adequado para a criança vivenciar e sentir sua relação com o meio. Dentro do cenário apresentado, as atividades psicomotoras que levam a criança a tomar consciência de seu corpo, devem ser praticadas desde o início da infância. Objetivou-se verificar os efeitos da psicomotricidade na Educação Física e pratica de exercícios físicos para o desenvolvimento integral da criança. Este trabalho foi realizado por meio de leitura exploratória de materiais bibliográficos, baseada na análise de livros, revistas, artigos de sites (scielo e google acadêmico) que abordam a importância da psicomotricidade como ferramenta na Educação Física. Os resultados evidenciados foram que a psicomotricidade desenvolve as habilidades motoras quando trabalhada nas aulas de educação física, e colabora para o desenvolvimento afetivo, cognitivo e motor. Esse processo, ocorre gradativamente, ao longo do crescimento e maturação da criança. Deste modo, a psicomotricidade atua fornecendo subsídios para adaptação da criança as suas necessidades básicas. E assim, quando trabalhada no contexto escolar, estimula o desenvolvimento harmonioso e integral do ser. Ao verificar as pesquisas e estudos em torno de crianças com e sem dificuldades motoras, pode se concluir que a intervenção motora causa progressos consideráveis no desenvolvimento motor, cognitivo e afetivo, e que estes por sua vez, colaboram com as outras áreas de aprendizagem (leitura e escrita por exemplo) e com desenvolvimento integral da criança. As atividades psicomotoras devem ser utilizadas como aparato da educação física na educação infantil, já que existe, por parte da literatura um consenso de que tais atividades auxiliam a criança no seu desenvolvimento global.
\end{abstract}

Palavras-chave: Desenvolvimento motor; Cognitivo; Exercícios físicos; Crianças; Esportes.

\begin{abstract}
Physical Education appears with great responsibility at school, structuring the appropriate environment for children to experience and feel their relationship with the environment. Within the presented scenario, the psychomotor activities that lead the child to become aware of his body, must be practiced since the beginning of childhood. The objective was to verify the effects of psychomotricity in Physical Education and practice of physical exercises for the integral development of the child. This work was carried out by means of an exploratory reading of bibliographic materials, based on the analysis of books, magazines, website articles (scielo and google academic) that address the importance of psychomotricity as a tool in Physical Education. The results evidenced were that psychomotricity develops motor skills when worked in physical education classes, and collaborates for affective, cognitive and motor development. This process occurs gradually over the child's growth and maturation. In this way, psychomotricity works by providing subsidies for the child's adaptation to his basic needs. And so, when worked in the school context, it stimulates the harmonious and integral development of the being. When verifying research and studies around children with and without motor difficulties, it can be concluded that motor intervention causes considerable progress in motor, cognitive and affective development, and that these in turn, collaborate with other areas of learning (reading
\end{abstract}


and writing for example) and with the child's full development. Psychomotor activities should be used as an apparatus of physical education in early childhood education, since there is a consensus in the literature that such activities help children in their global development.

Keywords: Motor development; Cognitive; Physical exercises; Kids; Sports.

\section{Resumen}

La Educación Física aparece con gran responsabilidad en la escuela, estructurando el entorno adecuado para que los niños experimenten y sientan su relación con el entorno. Dentro del escenario presentado, las actividades psicomotoras que llevan al niño a tomar conciencia de su cuerpo, deben ser practicadas desde el inicio de la niñez. El objetivo fue verificar los efectos de la psicomotricidad en la Educación Física y el ejercicio físico para el desarrollo integral del niño. Este trabajo se realizó mediante una lectura exploratoria de materiales bibliográficos, a partir del análisis de libros, revistas, artículos de sitios web (scielo y google academic) que abordan la importancia de la psicomotricidad como herramienta en la Educación Física. Los resultados evidenciados fueron que la psicomotricidad desarrolla las habilidades motoras cuando se trabaja en las clases de educación física, y colabora para el desarrollo afectivo, cognitivo y motor. Este proceso ocurre gradualmente durante el crecimiento y la maduración del niño. De esta forma, la psicomotricidad funciona proporcionando subvenciones para la adaptación del niño a sus necesidades básicas. Y así, cuando se trabaja en el contexto escolar, estimula el desarrollo armónico e integral del ser. Al verificar investigaciones y estudios en torno a niños con y sin dificultades motoras, se puede concluir que la intervención motora provoca un avance considerable en el desarrollo motor, cognitivo y afectivo, y que estos a su vez, colaboran con otras áreas de aprendizaje (lectura y escritura por ejemplo) y con el pleno desarrollo del niño. Las actividades psicomotoras deben utilizarse como un aparato de educación física en la educación infantil, ya que existe un consenso en la literatura de que dichas actividades ayudan a los niños en su desarrollo global.

Palabras clave: Desarrollo motor; Cognitivo; Ejercicios físicos; Niños; Deportes.

\section{Introdução}

Conforme Soares (2015), a aprendizagem, necessita de construção mental complexa. É muito comum, crianças da mesma faixa etária, apresentarem níveis diferentes de aprendizagem no que tange a leitura e escrita, ou qualquer outro tipo de aprendizagem que apresenta exigência específica. Essa variabilidade é comum e frequente, mostrando a oscilação da maturação entre as crianças, de forma que, a maioria delas, apenas precisaria de mais tempo para desenvolver as capacidades básicas respectivas à linguagem.

Ciasca (1994), afirma que os diferentes tipos de aprendizagem não são formados apenas por circuitos neurais diferentes, apresentando mecanismos neurais em comum e fundamentais. Com isso, Soares (2015), hipotetiza que o desenvolvimento neurológico em um todo pode acontecer, independente da especificidade da aprendizagem que a criança está sendo submetida e que algumas capacidades podem ser estimuladas por novas habilidades que vão sendo adquiridas por meio dos estímulos fornecidos, facilitando a aprendizagem motora no geral.

O atraso no desenvolvimento da coordenação motora, chega a afetar até $50 \%$ dos escolares que em consequência disso, apresentam problemas de aprendizagem, sugerindo desarranjo neural e dificuldade de integração sensório-motora da informação. Pode-se encontrar nesse grupo a ocorrência de disgrafia pelas dificuldades apresentadas de coordenação e destreza manuais. Já foi demonstrado que a dificuldade da leitura tem estreita relação com a dificuldade da criança em repetir ritmos e que os atrasos motores podem estar relacionados com os casos de dislexia e atraso na leitura (Soares, 2015).

Possíveis atrasos no desenvolvimento das habilidades motoras, podem afetar aspectos relacionados as atividades escolares e consequentemente influenciar de forma negativa a aprendizagem em um todo (Medina-Papst e Marques, 2010). Os autores ainda frisam o importante papel da Educação Física na escola, colaborando com o desenvolvimento humano, de modo especial com desenvolvimento motor.

Dentro do cenário apresentado, as atividades psicomotoras que levam a criança a tomar consciência de seu corpo, da lateralidade, a situação no espaço e como dominar o tempo, a adquirir habilidades e de seus gestos e movimentos, devem ser praticadas desde o início da infância, e conduzida com perseverança (Souza, et al., 2014). Objetivou-se neste estudo verificar os efeitos da psicomotricidade na Educação Física e pratica de exercícios físicos para o desenvolvimento integral da criança. 


\section{Metodologia}

De acordo com Estrela (2018), a presente pesquisa trata-se de uma revisão bibliográfica de natureza qualitativa, para o levantamento bibliográfico foram utilizados artigos científicos disponíveis online em formato de pdf, entre os anos (1980 2020). A busca dos artigos foi realizada na base de dados do Google acadêmico no período de agosto/2020 a janeiro/2021. Para a busca literária foram utilizados os seguintes descritores: Educação física, obesidade infantil, a importância da educação física, benefícios promovidos pela prática de exercícios físicos no combate à obesidade. Após a leitura exploratória, realizou-se leitura seletiva e analítica do material, verificando a relevância do conteúdo encontrado para a elaboração do presente trabalho.

\section{Revisão}

\subsection{Desenvolvimento motor}

Carvalho (2008), caracteriza o desenvolvimento motor como alterações nos padrões de movimento que ocorrem com o passar dos anos. Aquino, et al. (2012), corrobora afirmando que o desenvolvimento da criança ocorre de forma gradativa ao longo do seu crescimento e de sua capacidade de se adaptar as suas necessidades básicas. Gallahue e Ozmun (2005), afirmam que as habilidades conquistadas, continuadamente, sem pular etapas, arquitetam o desenvolvimento motor, sendo este definido como modificações na conduta motora durante a vida.

Compreendendo os níveis do desenvolvimento, pode-se organizar a metodologia e estrutura do ensino de forma que a criança seja propensa a se desenvolver com agilidade e desembaraço, obedecendo seus limites mentais e físicos (Silva, 2013).

O estudo das etapas de desenvolvimento motor da criança, de acordo com Barreto (2000), mostra que o movimento é uma das primeiras aprendizagens que a criança passa a ter, desde o primeiro estágio, que vai de 0 a 6 meses de idade. Com 6 meses de idade a criança geralmente aprende a sentar. A evolução dessas etapas, que são divididas em quatro e compreendem a fase desde 0 a 8 anos de idade, torna-se relevante para os estudos da psicomotricidade, uma vez que previne problemas da aprendizagem e reeduca os tônus, a postura, a lateralidade e o ritmo.

O meio em questão, influencia o desenvolvimento do indivíduo, podendo gerar interferências positivas ou negativas. Quando a interferência é positiva, o desenvolvimento motor, cognitivo e social, acontece na infância, de forma mais veemente (Soares, et al., 2015).

O desenvolvimento motor está relacionado às áreas cognitiva e afetiva do comportamento humano, sendo influenciado por muitos fatores. Dentre eles destacam os aspectos ambientais, biológicos, familiar, entre outros. Esse desenvolvimento é a contínua alteração da motricidade, ao longo do ciclo da vida, proporcionada pela interação entre as necessidades da tarefa, a biologia do indivíduo e as condições do ambiente (Gallahue, 2005).

Como a aptidão física e o desenvolvimento, de uma forma geral, interligam-se diversos estudos revelam a importância de direcionar a atenção para tais fatores. Desenvolvendo a aptidão física, as capacidades funcionais se ampliam concomitantemente, colaborando para realização de atividades rotineiras e nas outras formas de aprendizagem (Silva, 2013). De acordo com De Melo, et al., (2020), os exercícios de natação realizado com crianças e adolescente pode melhorar o desenvolvimento da criança, estruturando um ambiente facilitador para a mesma, no aspecto motor, aspecto psicológico e social da criança.

Pensando em preparar a criança para uma aprendizagem futura condizente com sua necessidade do futuro, pode-se trabalhar com a psicomotricidade nas aulas de Educação Física. Assim sendo, o desenvolvimento psicomotor ocorrerá por meio de estímulos das habilidades, como equilíbrio, coordenação motora, lateralidade, noção espaço temporal, entre outros (Campão \& Cecconcello, 2008).

Para o desenvolvimento global da criança, as atividades psicomotoras são muito importantes, estimulando a interação de diversas funções motoras. Por meio desse processo de estimulação a criança desenvolve a consciência de si mesma e do 
mundo exterior, ajudando também na conquista de sua independência. Com um bom controle motor, a criança consegue conhecer o mundo exterior, vivenciando experiências concretas que farão parte de seu desenvolvimento intelectual. Por meio de seu corpo, o mundo externo é sentido e descoberto pela criança. Esse processo é facilitado com a ajuda de profissionais competentes e comprometidos que trabalham o desenvolvimento motor das crianças, no contexto escolar, em especial, o professor de Educação Física (Rosa Neto, 2002).

\subsection{Psicomotricidade}

A psicomotricidade é sustentada por três conhecimentos básicos: o movimento, o intelecto e o cognitivo. As aquisições cognitivas, motoras e afetivas estão relacionadas com o processo de maturação do indivíduo. Pode-se assim, definir Psicomotricidade como uma ciência que estuda a relação do homem em movimento com o mundo interno e externo (Galvâo, 1995).

Desenvolver a criança de forma integral é o objetivo da psicomotricidade, para isso estuda o homem e as atividades que porventura podem servir de ferramentas para o desenvolvimento de aspectos físicos, mentais, sociais, psicológicos e culturais (Aquino, et al., 2012).

A psicomotricidade possui vários conceitos. Muitos deles até confundidos entre as pessoas que acreditam ser apenas algo relativo ao movimento corporal. Na realidade, o conceito de psicomotricidade vai muito além da simples movimentação do corpo, uma vez que contribui de maneira significativa para a formação e estruturação de todo o esquema corporal. Ela pode ser definida como a consciência de que corpo, mente e espírito estão intimamente conectados, mediante a ação (Souza, et al., 2014).

A psicomotricidade é a ciência da educação que tem como objetivo procurar educar o movimento, ao mesmo tempo que envolve as funções do pensamento. Portanto, o intelecto se constrói a partir do exercício físico, que é importante e fundamental para o desenvolvimento do corpo, mente e da emotividade. Sem o suporte psicomotor, o pensamento não poderá ter acesso aos símbolos e à abstração (Machado \& Nunes, 2011).

Sendo assim, Souza, et al., (2014), corroboram, dizendo que a psicomotricidade é a capacidade psíquica de realizar movimentos, não se tratando da realização do movimento propriamente dito, mas sim da atividade psíquica, que transforma a imagem em ação, e consequentes estímulos para os procedimentos musculares adequados.

Existe grande importância em aplicar atividades psicomotoras em crianças de 6 a 12 anos; é nessa fase que a criança está em grande período de exploração, e ela utiliza cada vez mais as habilidades motoras e cognitivas. É nesta fase que as crianças devem estar em constante movimento, aplicando-os em diferentes atividades que possam estimular sua aprendizagem (Souza, et al., 2014).

Com intuito de fornecer as crianças um desenvolvimento harmonioso e integral, a psicomotricidade deve ser trabalhada nas aulas de educação física. Elementos psicomotores como coordenação motora, orientação espaço temporal, equilíbrio, lateralidade e esquema corporal podem ser desenvolvidos através de aulas educação física. Além do desenvolvimento das habilidades psicomotoras, tais aulas podem auxiliar no processo de aprendizagem. À medida que a criança cresce e se desenvolve de forma gradativa, vai se adaptando as necessidades básicas (Aquino, et al., 2012).

Campão e Cecconello (2008), reforçam essa afirmação dizendo que para uma aprendizagem adequada, é necessário trabalhar com a psicomotricidade nas aulas de educação física, desenvolvendo assim o potencial da criança e possibilitando que no futuro essas habilidades sejam utilizadas em inúmeras situações.

Silva e Borges (2013), apontam que jogos na educação infantil que estimulam as atividades motoras, podem prevenir ou melhorar problemas de dificuldade em escrita e leitura. Oliveira (1992), vai além, afirmando que para uma boa alfabetização, as crianças precisam de atividades psicomotoras. E, na mesma linha de raciocínio, Negrine (1980), colabora 
afirmando que para uma aprendizagem ideal da leitura e escrita, os exercícios psicomotores surgem como ferramentas fundamentais.

De forma preventiva, a psicomotricidade pode ser utilizada na educação infantil. Problemas com alfabetização, dificuldades relacionadas na identificação de palavras e falta de concentração podem ser evitadas por meio de sua utilização (Molinari \& Sens, 2003).

Pesquisadores têm obtido resultados positivos ao dar ênfase na psicomotricidade como ferramenta na educação infantil, principalmente ao avaliar a criança na fase escolar (Aquino, et al., 2012). Nesse sentido Meur e Staes (1984), afirmam a atividade física como instrumento essencial para construir o intelecto, sendo impossível separar o desenvolvimento intelectual e afetivo das funções motoras.

Os materiais diversos, o componente lúdico e o espaço físico são fundamentais no processo, já que, conforme Kamila, et al., (2010), relacionando com o meio, adaptando aos estímulos e as adversidades, as crianças desenvolvem suas habilidades motoras. Dessa forma, o exercício aparece como aparato imprescindível, estimulando o desenvolvimento do ser humano.

Assim sendo, a psicomotricidade nas aulas de Educação Física, surge com caráter relevante, promovendo a evolução das habilidades motoras e cognitivas e colaborando de forma concomitante na interação social (Silva, 2013). O autor cita jogos lúdicos, brincadeiras e atividades como pular amarelinha, corda e jogos de equilíbrio por exemplo, como fundamentais na infância, auxiliando na melhoria da aptidão física, do desenvolvimento socioafetivo e do desenvolvimento motor. Tais fatores demonstram que a escola, apresenta papel significativo, quando adota uma metodologia voltada a esses objetivos.

Além das habilidades motoras, a criatividade, o raciocínio e a socialização são fortalecidos pelas atividades psicomotoras. Como tem por objetivo o completo desenvolvimento do ser humano nos três aspectos (motor, afetivo e cognitivo), a psicomotricidade aparece como ferramenta fundamental da educação física na educação infantil (Brasil, 1998).

O profissional de Educação Física precisa estar consciente, no que tange a psicomotricidade, que as crianças passam pelos mesmos processos de maturação e crescimento, podendo ocorrer, porém, oscilação na velocidade de assimilação dos processos. Dessa forma, deve-se trabalhar de forma progressiva, dando prioridade ao básico e partindo posteriormente para o mais complexo. Desprovida do conhecimento das etapas do desenvolvimento na aprendizagem, a educação física escolar se torna incapaz de colaborar e suprir as necessidades do desenvolvimento motor (Daolio, 2010).

No Quadro 1. Estudos realizados com intervenção em crianças, para avaliar o desenvolvimento psicomotor, está descrito alguns estudos realizados para avaliação do desenvolvimento psicomotor em crianças com idades e exercícios físicos variados. 
Quadro 1. Estudos realizados com intervenção em crianças, para avaliar o desenvolvimento psicomotor.

\begin{tabular}{|c|c|c|c|c|}
\hline Amostra & Objetivo & Testes aplicados & Conclusão & 产 \\
\hline $\begin{array}{l}86 \text { crianças entre } 6 \text { e } \\
10 \text { anos, de ambos os } \\
\text { sexos }\end{array}$ & $\begin{array}{l}\text { Avaliar as } \begin{array}{r}\text { funções } \\
\text { psicomotoras } \\
\text { perceptual e dominância }\end{array} \\
\text { lateral) em crianças entre } 6 \mathrm{e} \\
10 \text { anos de idade. }\end{array}$ & $\begin{array}{l}\text { Sistema } r \text { de } \\
\text { avaliação de } \\
\text { algumas funções } \\
\text { psicomotoras, } \\
\text { (motora, perceptual } \\
\text { e dominância } \\
\text { lateral) para } \\
\text { crianças entre } 6 \text { e } \\
10 \text { anos de idade. } \\
\end{array}$ & $\begin{array}{l}\text { A população estudada apresentou } \\
\text { bom desenvolvimento da } \\
\text { coordenação motora fina, porém com } \\
\text { dificuldade na realização de } \\
\text { atividade específica que testava tal } \\
\text { função. }\end{array}$ & 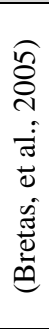 \\
\hline $\begin{array}{l}22 \text { crianças (13 com } \\
\text { queixa e } 9 \text { sem queixa } \\
\text { de dificuldade de } \\
\text { aprendizagem) com } \\
\text { idade entre } 7 \text { e } 11 \\
\text { anos. }\end{array}$ & $\begin{array}{l}\text { Avaliar e comparar o } \\
\text { desempenho motor de crianças } \\
\text { com e sem dificuldade de } \\
\text { aprendizagem } \\
\text { intervenção com aulas de } \\
\text { Educação Física direcionada. }\end{array}$ & $\begin{array}{l}\text { Práticas voltadas à } \\
\text { esgrima } \\
\text { atividades } \\
\text { circenses. } \\
\text { Realizou-se } \\
\text { avaliação motora, } \\
\text { por meio da Escala } \\
\text { de } \\
\text { Desenvolvimento } \\
\text { Motor (EDM) de } \\
\text { Rosa Neto. }\end{array}$ & $\begin{array}{l}\text { Indica-se que são possíveis } \\
\text { intervenções de profissionais da } \\
\text { Educação Física visando auxiliar } \\
\text { crianças com dificuldades de } \\
\text { aprendizagem e, motivando-as para à } \\
\text { prática de atividades físicas. }\end{array}$ & 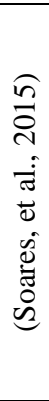 \\
\hline $\begin{array}{l}147 \text { adolescentes do } \\
\text { ensino médio ( } 78 \text { da } \\
\text { primeira série e } 69 \text { da } \\
\text { segunda série; } 73 \\
\text { meninos e } \\
\text { meninas com } 16 \text { e } 17 \\
\text { anos, } \\
\text { respectivamente). }\end{array}$ & $\begin{array}{l}\text { Pesquisar uma resposta à } \\
\text { questão se existe uma relação } \\
\text { entre as notas escolares que } \\
\text { refletem as habilidades } \\
\text { humanística, síntese, ecológica } \\
\text { e habilidades físicas, e } \\
\text { melhores competências em } \\
\text { termos de velocidade motora e } \\
\text { de potência, em alunos do } \\
\text { ensino médio. }\end{array}$ & $\begin{array}{l}\text { Teste de toque na } \\
\text { placa: velocidade } \\
\text { de membros } \\
\text { superiores. Teste } \\
\text { de Fleishman: } \\
\text { velocidade dos } \\
\text { membros } \\
\text { inferiores. Potência } \\
\text { dos membros } \\
\text { superiores: } \\
\text { lançamento da } \\
\text { medicine } \\
\text { Potência } \\
\text { membros } \\
\text { inferiores: } \\
\text { impulsão } \\
\text { horizontal. }\end{array}$ & $\begin{array}{l}\text { Sugere-se que maior atenção deve } \\
\text { ser dada para as possíveis relações } \\
\text { entre desempenho escolar e } \\
\text { habilidades motoras em crianças e } \\
\text { adolescentes. }\end{array}$ & 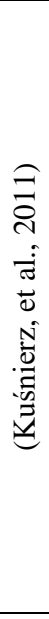 \\
\hline $\begin{array}{l}324 \text { alunos de ambos } \\
\text { os sexos ( } 3 \text { a } 5 \text { anos } \\
\text { de idade) de } 9 \text { turmas } \\
\text { públicas do jardim de } \\
\text { infância no Porto, } \\
\text { Portugal. }\end{array}$ & $\begin{array}{l}\text { Investigar a influência do } \\
\text { plano estruturado de Educação } \\
\text { Física no desenvolvimento } \\
\text { psicomotor de pré-escolares de } \\
3 \text { a } 5 \text { anos. }\end{array}$ & $\begin{array}{l}\text { Testes } \\
\text { psicomotores: } \\
\text { Coordenação } \\
\text { equilíbrio, } \\
\text { esquema corporal, } \\
\text { lateralidade, } \\
\text { organização } \\
\text { espacial } \\
\text { e temporal. }\end{array}$ & $\begin{array}{l}\text { A educação física estruturada é } \\
\text { importante para desenvolvimento } \\
\text { psicomotor de crianças em idade pré- } \\
\text { escolar. }\end{array}$ & 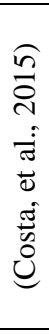 \\
\hline $\begin{array}{l}24 \text { crianças de ambos } \\
\text { os sexos com idade } \\
\text { entre } 6 \text { a } 12 \text { anos. }\end{array}$ & $\begin{array}{l}\text { Analisar a interferência de } \\
\text { atividades psicomotoras no } \\
\text { auxílio do } \\
\text { desenvolvimento cognitivo e } \\
\text { motor de crianças de } 6 \text { a } 12 \\
\text { anos. }\end{array}$ & $\begin{array}{l}\text { Testes } \\
\text { psicomotores: } \\
\text { tonicidade, } \\
\text { equilíbrio, } \\
\text { lateralidade, noção } \\
\text { do corpo, } \\
\text { estruturação } \\
\text { espaço-temporal e } \\
\text { praxia global e } \\
\text { fina. }\end{array}$ & $\begin{array}{l}\text { A prática de atividades psicomotoras } \\
\text { auxilia no desenvolvimento } \\
\text { cognitivo e motor em crianças de } 6 \text { a } \\
12 \text { anos. }\end{array}$ & 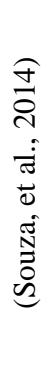 \\
\hline
\end{tabular}




\begin{tabular}{|c|c|c|c|c|}
\hline $\begin{array}{l}126 \text { alunos, de ambos } \\
\text { os sexos, com cinco } \\
\text { anos de idade. }\end{array}$ & $\begin{array}{l}\text { Verificar a influência da aula } \\
\text { de Educação Física no } \\
\text { Desenvolvimento Psicomotor } \\
\text { de alunos do ensino pré- } \\
\text { escolar de cinco anos. }\end{array}$ & $\begin{array}{l}\text { Bateria de testes: } \\
\text { coordenação } \\
\text { equilíbrio, } \\
\text { esquema corporal, } \\
\text { lateralidade, } \\
\text { organização } \\
\text { espacial } \\
\text { temporal. }\end{array}$ & $\begin{array}{l}\text { A Educação Física estruturada é } \\
\text { importante para o desenvolvimento } \\
\text { psicomotor da criança em idade pré- } \\
\text { escolar. }\end{array}$ & 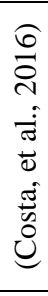 \\
\hline $\begin{array}{l}18 \text { alunos com a faixa } \\
\text { etária de } 02 \text { a } 03 \text { anos } \\
\text { de um } \quad \text { Centro } \\
\text { Municipal } \\
\text { Educação Infantil do } \\
\text { Município de Nova } \\
\text { Esperança. }\end{array}$ & $\begin{array}{l}\text { Analisar a importância do } \\
\text { brincar para desenvolver e } \\
\text { proporcionar na criança o lazer } \\
\text { e a aprendizagem }\end{array}$ & $\begin{array}{l}\text { Brincadeiras } \\
\text { envolviam ae } \\
\text { habilidades básicas } \\
\text { na área motora } \\
\text { (coordenação } \\
\text { global e fina); } \\
\text { adaptação; } \\
\text { Linguagem e } \\
\text { pessoal - social. }\end{array}$ & $\begin{array}{l}\text { Quando a criança é estimulada a } \\
\text { explorar, sentir e experimentar, será } \\
\text { capaz de construir sua própria } \\
\text { aprendizagem funcionando como } \\
\text { uma fonte de estímulos para } \\
\text { desenvolver sua capacidade criativa. }\end{array}$ & 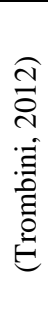 \\
\hline
\end{tabular}

Fonte: Autores.

Analisando os resultados obtidos pelos autores no quadro acima, pode-se afirmar que a Educação Física escolar colabora de forma eficaz na aprendizagem de modo geral nas crianças, colaborando com seu desenvolvimento, não limitando apenas ao desenvolvimento motor, mas também com cognitivo e afetivo. E, nessa perspectiva, enxergando as aulas de Educação Física por outro prisma, não mais da forma distorcida como foi apresentada ao longo dos anos, como aulas voltadas à diversão ou apenas de brincadeiras, mas como uma matéria essencial da escola, tendo a mesma relevância de qualquer outra matéria. O componente lúdico é essencial quando se trata de aulas de Educação Física, porém é apenas um dos componentes, sendo muito limitada quando vista apenas por esse ângulo obsoleto, que já ficou, ou pelo deveria ter ficado para trás.

Soares, et al., (2015), compararam a performance motora de 22 crianças, que apresentavam ou não dificuldades na aprendizagem, após a intervenção das aulas de Educação Física. Desta forma, concluíram que a presença e intervenção do profissional de Educação Física é fundamental e que por meio da motivação, faz-se possível transformar a dificuldade em aprendizado em crianças que apresentam déficits motores e atrasos de aprendizagem.

Assim, compreende-se com essa informação, que as aulas de Educação Física, colaboraram para intensificar o desenvolvimento motor daqueles que participaram. Evidencia-se também por meio de tais resultados, que aqueles que apresentavam dificuldades de aprendizagem, foram os mais favorecidos (Soares, et al., 2015).

Para Fonseca (1988), a noção de esquema corporal traduz um processo psicofisiológico que tem origem nos dados sensoriais que são evidenciados e fornecidos pelas estruturas motoras, resultantes do movimento pelo sujeito.

Fonseca (2009), por meio de seus estudos, lança algumas bases para a compreensão do primeiro processo humano de aprendizagem e apropriação do real, ou seja, a motricidade, meio pelo qual a inteligência humana se desenvolveu e se materializou.

Pela fala do autor, entende-se que a inteligência, os processos de aprendizagem (leitura, escrita, raciocínio) e desenvolvimento dos sentidos se desenvolvem através da motricidade. O movimento determina o desenvolvimento de todas as outras áreas do indivíduo e explica a evolução da espécie. Inclusive o desenvolvimento intelectual, ocorre concomitante ao desenvolvimento motor. Isso justifica a importância de fornecer estímulos e manter as crianças ativas, sendo a inércia, estagnação das outras capacidades e da aprendizagem.

Sabe-se que o cérebro humano inconcluso à nascença é estruturado e rearranjado pela função motora nos primeiros anos de vida. Inúmeros trabalhos de investigação sugerem que as futuras faculdades de aprendizagem decorrem das primeiras aquisições motoras, a integração sensorial se transcende em integração psicomotora, base da organização intrínseca do cérebro que se transforma e substitui em várias motricidades para materializar os seus processos organizativos (Fonseca, 2009).

Conforme Rosa Neto (2002), a psicomotricidade é a interação de diversas funções neurológicas, motrizes e psíquicas. 
É essencialmente, a educação do movimento, ou por meio do movimento, que provoca melhor utilização das capacidades motoras e psíquicas. A psicomotricidade é a ciência da educação que tem como objetivo procurar educar o movimento, ao mesmo tempo que envolve as funções do pensamento.

Com esse mesmo ponto de vista, Machado e Nunes (2011), afirmam que o intelecto se constrói a partir do exercício físico, que é muito importante e fundamental para o desenvolvimento do corpo, mente e da emotividade e que sem o suporte psicomotor, o pensamento não poderá ter acesso aos símbolos e à abstração.

Kuśnierz, et al., (2011), avaliaram 147 adolescentes do ensino médio e após intervenção, afirmam que maior atenção deve ser dada para as possíveis relações entre desempenho escolar e habilidades motoras em crianças e adolescentes. O estudo propôs uma possível inter-relação entre as notas escolares e o desempenho físico concluindo que as escolas devem ser reconhecidas como importante centro social de promoção de atividade física em adolescentes, afirmando que a atividade motora regular durante a infância e adolescência está associada à melhora em numerosas e variáveis psicológicas.

Costa, et al., (2015), avaliaram 324 alunos de ambos os sexos e afirmam que é essencial desconstruir a ideia comumente aceita, as vezes apoiada por acadêmicos, de que as crianças são espontaneamente ativas. Ressaltam que a atividade física gera interação das crianças com o mundo exterior por meio de seu desenvolvimento geral, que pode ser motivado pelas aulas de Educação Física estruturadas.

Souza, et al., (2014), analisaram por meio de testes psicomotores, 24 crianças de ambos os sexos com idade entre 6 a 12 anos. O segundo teste foi realizado três meses após a realização do primeiro teste. Durante estes três meses as crianças realizaram atividades psicomotoras e a maioria das crianças tiveram grande melhora na pontuação no segundo teste. Das vinte e quatro crianças testadas, vinte delas evoluíram em suas pontuações, principalmente nas categorias de equilíbrio, lateralização, noção do corpo, estruturação espaço-temporal e praxia fina. Os autores concluíram então que a prática de atividades psicomotoras, auxiliam no desenvolvimento cognitivo e motor em crianças de 6 a 12 anos.

Costa, et al., (2016), avaliaram 126 alunos, de ambos os sexos, com cinco anos de idade. No pré-teste, as variáveis de esquema corporal, organização espacial e organização temporal, apresentaram pontuações superiores no grupo controle em relação ao grupo experimental. No entanto, no pós-teste, após a implementação do programa específico de Educação Física, o grupo experimental obteve pontuações mais elevadas do que o grupo controle. Concluíram que a Educação Física estruturada é importante para o desenvolvimento psicomotor da criança em idade pré-escolar.

Trombini (2012), avaliou 18 alunos com a faixa etária de dois a três anos de um Centro Municipal de Educação Infantil do Município de Nova Esperança. A autora afirma que as atividades propostas em sala de aula, foram essenciais para o aprimoramento das habilidades básicas e psicomotricidade dos alunos, realçando, assim para as professoras e funcionários que fazem parte deste ambiente educacional, que a ampliação das informações sobre a atividade física, são importantes para o desenvolvimento das crianças desde sua personalidade até sua ação no meio ao qual fazem parte. A autora conclui que quando a criança é estimulada a explorar, sentir e experimentar, será capaz de construir sua própria aprendizagem, funcionando como fonte de estímulos para desenvolver sua capacidade criativa.

Esses dados comprovam a hipótese de que crianças com desenvolvimento motor inferior ao esperado pela idade, possuem também dificuldades de aprendizagens em outras áreas, já que, como foi abordado, o intelecto se constrói a partir da motricidade e que sem o suporte psicomotor, o pensamento estará prejudicado. Concomitante a isso, demonstrou-se também que ao serem estimuladas as crianças revelaram melhor desempenho, evidenciando que as aulas de Educação Física de forma adequada são ferramentas primordiais na evolução e aperfeiçoamento das capacidades psicomotoras e cognitivas.

\section{Considerações Finais}

Ao verificar as pesquisas e estudos acerca de crianças com e sem dificuldades motoras, que foram submetidas a 
diversos testes e exercícios e apresentaram desempenho estatisticamente relevante, pode-se concluir que a intervenção motora causa progressos consideráveis no desenvolvimento motor, cognitivo e afetivo, e que estes por sua vez, colaboram com as outras áreas de aprendizagem (leitura e escrita por exemplo) e com desenvolvimento integral da criança.

Pode-se apontar também, que as atividades psicomotoras devem ser utilizadas como aparato da educação física na educação infantil, já que existe, por parte da literatura um consenso de que tais atividades auxiliam a criança no seu desenvolvimento global. O movimento auxilia o desenvolvimento de todas as outras áreas do indivíduo, inclusive o desenvolvimento intelectual, que ocorre concomitante ao desenvolvimento motor. Isso justifica a importância de fornecer estímulos e manter as crianças ativas. Inércia é estagnação das outras capacidades e da aprendizagem.

À primeira vista o que parece faltar é a consolidação de uma cultura da prática de atividades física regulares, a qual poderia ser estimulada desde a primeira infância, no seio familiar e, consecutivamente, no meio educacional promovido pela escola. Portanto, este estudo suscita a comunidade científica a considerar este aspecto e aprofundar pesquisas nesta temática.

Após o levantamento bibliográficos realizados de natureza qualitativa, sugerimos para futuras pesquisas uma revisão sistematizada de natureza quantitativa, para que possa mensurar estatisticamente os resultados de estudos aplicados a voluntários em pesquisas com intervenção.

\section{Referências}

Aquino, M. F. S., Browne, R. A. V., Sales, M. M., \& Dantas, R. A. E. (2012). A psicomotricidade como ferramenta da educação física na educação infantil. RBFF-Revista Brasileira de Futsal e Futebol, 4(14).

Barreto, S. D. J. (2000). Psicomotricidade, educação e reeducação. Editora Acadêmica.

Basei, A. P. (2008). A Educação Física na Educação Infantil: a importância do movimentar-se e suas contribuições no desenvolvimento da criança. Revista Iberoamericana de Educación, 47(3), 1-12.

Brasil, M. E. C. (1998). Referencial curricular nacional para a educação infantil. MEC/SEF.

Bretas, J. R. D. S., Pereira, S. R., Cintra, C. D. C., \& Amirati, K. M. (2005). Avaliação de funções psicomotoras de crianças entre 6 e 10 anos de idade. Acta paulista de enfermagem, 18(4), 403-412.

Campão, D. D. S., \& Cecconello, A. M. (2008). A contribuição da educação física no desenvolvimento psicomotor na educação infantil. Lecturas, Educación Física y Deportes. Revista Digital. Ano, 13.

Carvalho, B., \& de Sá, C. D. S. C. (2008). Influência da prática lúdica no equilíbrio e na coordenação motora de crianças influence of playful activity practice in the balance and the motor coordination in children. Revista de Atenção à Saúde, 6(18).

Ciasca, S. M. (1994). Distúrbios e dificuldades de aprendizagem em crianças: análise do diagnóstico interdisciplinar.

Costa, H. T., Abelairas-Gomez, C., Arufe-Giráldez, V., Pazos-Couto, J. M., \& Barcala Furelos, R. (2015). Influence of a physical education plan on psychomotor development profiles of preschool children.

Costa, H. T., Gonçalves, J. F. S., Pimenta, P. S., \& Arufe-Giraldez, V. (2016). Influência da educação física no desenvolvimento psicomotor de crianças com cinco anos de idade. Nuances: estudos sobre Educação, 27(3), 79-100.

Daolio, J. (2010). Educação física eo conceito de cultura. Editora Autores Asociados LTDA.

De Melo, Janaína Magda Pinto et al. Benefícios da natação para crianças e adolescentes. Brazilian Journal of Development, 6, 62511-62519, 2020.

Estrela, C. (2018). Metodologia Científica: Ciência, Ensino, Pesquisa. Editora Artes Médicas.

Fonseca, V. (2009). Psicomotricidade: filogênese, ontogênese e retrogênese. Digitaliza Conteudo. Fonseca, V. D. (1988). Psicomotricidad y psiconeurologia: introdución al sistema psicomotor humano. Rev Estudios Experiencias (Madrid), 30(1), 25-43.

Gallahue, D. L., Ozmun, J. C., \& Goodway, J. D. (2013). Compreendendo o desenvolvimento motor-: bebês, crianças, adolescentes e adultos. AMGH Editora. Gallahue, D., \& Ozmun, J. (2005). Compreendendo o desenvolvimento motor: bebês, crianças, adolescentes e adultos (Phorte Ed.).

Galvão, I. (1995). Henri Wallon: uma concepção dialética do desenvolvimento infantil. Vozes.

Kamila, A. P. F., Maciel, R. A., Mello, L. D. A., \& Souza, R. A. A. (2010). A estimulação psicomotora na aprendizagem infantil.

Kuśnierz, C., Glaner, M. F., Tukiendorf, A., \& Szczegielniak, J. (2011). A possible relationship between school performance and motor skills: a neural network approach. Revista Brasileira de Cineantropometria \& Desempenho Humano, 13(5), 373-377. 
Research, Society and Development, v. 10, n. 8, e59310817982, 2021

(CC BY 4.0) | ISSN 2525-3409 | DOI: http://dx.doi.org/10.33448/rsd-v10i8.17982

Machado, J. R. M., \& Nunes, M. V. D. S. (2011). 100 jogos psicomotores: uma prática relacional na escola. Wak Editora.

Medina-Papst, J., \& Marques, I. (2010). Avaliação do desenvolvimento motor de crianças com dificuldades de aprendizagem. Rev Bras Cineantropom Desempenho Hum, 12(1), 36-42.

Meur, A., Staes, S., Galuban, A. M. I., \& Ono, S. (1984). Psicomotricidade: educação e reeducação: níveis maternal e infantil.

Molinari, A. D. P., \& Sens, S. M. (2003). A Educação Física e sua Relação com a Psicomotricidade. Revista PEC, 3(1), 85-93.

Negrine, A. (1980). A educação Física e a educação psicomotriz. Revista Brasileira de Educação Física e Desportos. MEC, $44,60-63$.

Nogueira, L. A., de Carvalho, L. A., \& Pessanha, F. C. L. (2007). A psicomotricidade na prevenção das dificuldades no processo de alfabetização e letramento. Perspectivas Online 2007-2011, 1(2).

Oliveira, G. D. C. (1992). Psicomotricidade: um estudo em escolares com dificuldades em leitura e escrita.

Rosa Neto, F. (2002). Manual de avaliação motora (Vol. 1). Artmed-Artes Médicas.

Silva Brêtas, J. R., Pereira, S. R., de Cássia Cintra, C., \& Amirati, K. M. (2005). Avaliação de funções psicomotoras de crianças entre 6 e 10 anos de idade. Acta paulista de enfermagem, 18(4), 403-412.

Silva, D. A. (2013). A importância da psicomotricidade na educação infantil.

Soares, D. B., Porto, E., Marco, A. D., Azoni, C. A. S., \& Capelatto, I. V. (2015). Influência da atividade física no desempenho motor de crianças com queixas de dificuldades de aprendizagem. Revista CEFAC, 17(4), 1132-1142.

Souza Lahti, F., de Carvalho, N. O., \& da Silva Vargas, L. A Importância de Atividades Psicomotoras para Crianças de 6 a 10 anos. Ciência em Movimento, 16(32), 39-57.

Trombini, L. M. (2012). A importância do brincar na educação infantil para a psicomotricidade: uma pesquisa de campo. 